\title{
BREHTOVA DRAMA KRUG KREDOM U PREVODU TATJANE ŠENK I JOVANA ĆIRILOVA
}

Naročito nakon odluke da se preseli u Istočni Berlin, Breht je postao meta ideoloških kontroverzi, koje su sve do pada Istočnog bloka neposredno uticale i na recepciju njegovih dela. Kada je reč o prevodnoj književnosti, sprega zvanične i kulturne politike vidljiva je kako u odabiru dela koja (ne)će biti prevedena tako i u načinu, odnosno, poetici prevođenja. Počev od praizvedbe Dobrog čoveka iz Sečuana (Der gute Mensch von Sezuan) 1954. godine, do danas su svi Brehtovi komadi koji spadaju u epsko pozorište prevedeni na srpski jezik, a među prevodima postoji i nekoliko onih o čijem postojanju nema nijednog traga $u$ sekundarnoj literaturi. U radu se predstavlja do sada nepoznati prevod Brehtove drame [Kavkaski] Krug kredom (Der kaukasische Kreidekreis, 1944) iz pera Tatjane Šenk i Jovana Ćirilova, koji se čuva u Biblioteci Srpskog narodnog pozorišta u Novom Sadu, i koji predstavlja svedočanstvo izuzetno bogate i raznovrsne prevodne recepcije ovog autora $u$ Srbiji. Na osnovu analize prevoda i rekonstrukcije prevodilačkog postupka, te tumačenja rezultata u okviru sistemskog konteksta, pokazalo se da su faktori koji utiču na način prihvatanja dela iz strane kulture u datom društveno-istorijskom kontekstu vidljivi i u samom prevodu.

Ključne reči: Bertolt Breht, Krug kredom, Tatjana Šenk, Jovan Ćirilov, prevodna recepcija, književno prevođenje, Biblioteka Srpskog narodnog pozorišta.

\section{UVOD}

Brehtov položaj kao društveno angažovanog pisca stoji u neraskidivoj vezi s prilikama na svetskoj društveno-političkoj pozornici. Iz tog razloga, on je i po okončanju Drugog svetskog rata, a naročito nakon što je 1949. godine doneo konačnu odluku da se preseli u Istočni Berlin, gde je proveo ostatak života, neprestano bio meta ideoloških kontroverzi, koje su sve do pada Istočnog bloka usmeravale recepciju njegovih dela, zavisno od političke orijentacije pojedinih

"anamitrevski@ff.uns.ac.rs 
zemalja (Knopf, 2006: 60-63). To se podjednako odnosilo na odluku da njegova dela (ne) budu prevedena, ali i na samu prevodilačku poetiku (Schneider, 1984: 143-168). Đurić tvrdi kako ,politika prevođenja nikada nije stvar pojedinca, već stvar kulture" (Đurić, 2002: 717-718). U posleratnoj Jugoslaviji situacija je bila izuzetno dinamična, što se odrazilo i na kulturnu politiku, a time i na književnost. Kako je drama u tom periodu najsporije napredovala (Deretić, 1987: 333), može se reći da su prevodi, koji dominiraju na repertoarima (Volk, 1990: 541-827), odigrali veoma važnu ulogu u obnovi pozorišnog života u Srbiji.

Recepcija Brehtovog epskog pozorišta počela je praizvedbom Dobrog čoveka iz Sečuana (Der gute Mensch von Sezuan, 1941), koji je prikazan 19. oktobra 1954. godine na sceni Beogradskog dramskog pozorišta (Pašić, 2007: 250). Ova premijera predstavljala je Brehtov proboj na jugoslovenske pozornice, nakon čega su se reditelji, prevodioci i izdavači ,utrkivali” čije ime će se naći tik uz Brehtovo na pozorišnim plakatima i koricama knjiga. Do danas su svi komadi koji spadaju u epsko pozorište prevedeni na srpski jezik, od kojih neki i više puta. Pored štampanih prevoda, postoji neuporedivo veći broj prevedenih drama iz svih faza Brehtovog stvaralaštva koje nisu publikovane, kao i nekoliko onih o čijem postojanju nema nijednog traga u sekundarnoj literaturi, bilo da je reč o novinskim napisima, kritikama ili naučnim publikacijama. Uprkos bogatoj recepciji, prevodima Brehtovih komada na srpski jezik, koji su u slučaju prihvatanja dela iz strane književnosti nužni posrednici i koji za čitaoce u ciljnoj kulturi predstavljaju zamenu za originalni tekst (Stolze, 2008: 145), posvećena je tek skromna naučna pažnja ${ }^{1}$. Ni u jednom radu nema pomena o Krugu kredom (Der kaukasische

${ }^{1}$ Up. Rnjak, D. (1972). Bertolt Brecht in Jugoslawien. Marburg: N. G. ELWERT VERLAG; Toma, S. (1979). Lirika Bertolta Brechta na srpskohrvatskom između dva rata (Nepublikovani magistarski rad). Filološki fakultet, Univerzitet u Beogradu, Beograd; Mitrevski, A. (2013). Prevođenje Brehtove drame Majka Hrabrost sa nemačkog na srpski jezik (Nepublikovani master rad). Filozofski fakultet, Univerzitet u Novom Sadu, Novi Sad; Mitrevski, A.-Petrović, Đ. (2014). Problem ekvivalentnosti u prevodu Brehtove drame Dobar čovek Sečuana. U: Anđelković, M. (2014). Savremena proučavanja jezika $i$ književnosti: zbornik radova sa V naučnog skupa mladih filologa Srbije, knj. 2. Kragujevac: Filološko-umetnički fakultet u Kragujevcu, 615-622; Mitrevski, A. (2016). Brehtova Majka Hrabrost u vremenu i prostoru. U: Gudurić, S.-Stefanović, M. (ured.) (2016). Jezici i kulture u vremenu i prostoru V: tematski zbornik. Novi Sad: Univerzitet u Novom Sadu, Filozofski fakultet, 149-154; Kovač, B.--Mitrevski, A. (2019). Beiß die Zähne zusammen! Phraseologismen in Berolt Brechts Die Dreigroschenoper und ihre Übersetzung ins Serbische. U: Gudurić, S.-Radić-Bojanić, B. (ured.) (2019). Jezici i kulture u vremenu $i$ 
Kreidekreis, 1944) Tatjane Šenk i Jovana Ćirilova (SNP, inv. br. 675/IV), iako je u pitanju jedno od ključnih Brehtovih dela. Ako se uzme u obzir odnos bivše Jugoslavije prema Sovjetskom Savezu (počev od 1948. godine), gde je radnja komada smeštena, a time i prema drugim zemljama Istočnog bloka, pored mogućnosti da su prevodioci ponudili prevod, ali da on nije bio zadovoljavajuć, nije isključeno ni da su razlozi bili uslovljeni vanjezičkim faktorima.

\section{1. Kavkaski krug kredom}

Pored drama Majka Hrabrost i njena deca (Mutter Courage und ihre Kinder, 1939), Dobri čovek iz Sečuana i Galilejev život (Leben des Galilei, 1955/6), Kavkaski krug kredom predstavlja rezultat zrele piščeve faze i vrhunac epskog pozorišta. Prve dve verzije ovog komada nastale su 1944. godine u Americi, i on se smatra jednim od Brehtovih pokušaja da osvoji Brodvej, a time i američku pozorišnu scenu (Brecht, Bd. 8, 1992: 450). Uz Dobrog čoveka iz Sečuana i mnoga druga dela, Kavkaski krug kredom ujedno predstavlja jedan u nizu primera za uticaj istočnjačke kulture u Brehtovom stvaralaštvu (Zobenica, 2015: 911-912).

Okosnicu drame čini priča iz „davne prošlosti” (Kittstein, 2008: 62) o služavki Gruše, koja se prepliće s pričom o seoskom pisaru i kurioznom sudiji Azdaku, situirane za „kratkih, zlatnih vremena, maltene pravednih” (SNP, inv. br. 675/IV: 77). One proizlaze iz predigre, koja čini okvirnu radnju vezanu za raspravu dvaju kolhoza oko plodne doline, koja je smeštena u sadašnjost (1944. godina). Osim u liku auktorijalnog pripovedača Arkadija Čajdzea, čiji izveštaj prožima scenski prikaz, spona između starog i novog, radnje „Predigre” i glavne radnje, ostvarena je i tematski, jer sukobljeni kolhozi na kraju odlučuju da dolina pripadne „onima koji su vični imanju” (SNP, inv. br. 675/IV: 77), kao što Azdak odlučuje u korist Gruše.

Centralni motiv kruga kredom, koji u delu služi kao eksperiment kako bi se utvrdilo koja od dve majke je ona prava, Breht je poznavao iz više izvora. Sama građa potiče iz kineske tradicije, ali postoje izvesne paralele između ove i starozavetne priče o Solomonu (solomonsko rešenje), kako je sam Breht istakao (Brecht, Bd. 24, 1991: 341-342). On se sa građom susreo dok je radio kao dramaturg u berlinskom pozorištu Dojčes teatar (Deutsches Theater), gde je „'komad po kineskom' Krug kredom” (Brecht, Bd. 8, 1992: 450) nemačkog pisca

prostoru VIII/2: tematski zbornik. Novi Sad: Univerzitet u Novom Sadu, Filozofski fakultet, $125-134$. 
Klabunda (Alfred Henschke) 1925. godine premijerno prikazan (Brecht, Bd. 8, 1992: 453). Osnovna izmena tiče se presude, prema kojoj kod Brehta, kojeg interesuje socijalni aspekat majčinstva, dete na kraju ne pripadne biološkoj majci.

Jezik je, u skladu s dramskim personalom i vremenom u koje je smeštena radnja, vrlo iznijansiran. Glavne razlike u dijalozima uočljive su između kolokvijalnog rečnika seljaka i vojske, koji karakteriše obilje frazeologizama i narodnih mudrosti, s jedne strane, i načina izražavanja koji neguje blazirana vlastela, a koji je manipulativan i obiluje ispraznim floskulama, s druge strane. Azdakov rečnik se od ostalih likova ističe po upotrebi vulgarizama, a tekst je, osim toga, protkan biblijskim izrazima $\mathrm{i}$ arhaizmima, koji naročito dominiraju $\mathrm{u}$ songovima. Hrvatski pisac Gustav Krklec je na osnovu svog prevodilačkog iskustva s Kavkaskim krugom kredom s pravom konstatovao kako Brehta „s jednakim zadovoljstvom mogu čitati pralje i univerzitetski profesori”, kao i to da je zbog navedenih stilskih osobenosti njegovih tekstova vrlo zahtevan za prevođenje (Rnjak, 1972: 48-49).

Delo je premijerno izvedeno na Karlton koledžu (Carleton-College Northfield/Minnesota) po prevodu Erika Bentlija (Eric Bentley) ${ }^{2}$, tek 1948. godine, dakle, nakon što je Breht napustio Sjedinjene Američke Države ${ }^{3}$. Nakon prve evropske premijere Kavkaskog kruga kredom u Gradskom pozorištu u Geteborgu (Göteborgs Stadttheater) 23. novembra 1951. godine, Berlinski ansambl (Berliner Ensemble) izveo je komad u Brehtovoj režiji 7. oktobra 1954. godine povodom obeležavanja Dana Nemačke Demokratske Republike ${ }^{4}$, kada je nastala i poslednja autorizovana verzija teksta, kao i muzika koju je komponovao Paul Desau (Paul Dessau).

Recepcija „Brehtovog najpoetičnijeg komada” (Knopf, 2006: 112) u Nemačkoj Demokratskoj Republici neočekivano je izazvala niz politički motivisanih kontroverzi, jer se izvođenje vremenski poklopilo s predstavljanjem nacrta novog porodičnog zakona, prema kojem se u slučaju razvoda dete dodeljivalo roditelju koji je bio politički podoban (Ullmann, 1976: 112-114). U Saveznoj Republici Nemačkoj, s druge strane, duži vremenski period komad je insceniran bez predigre (Kittstein, 2008: 61), jer sadrži jasne aluzije na oslobođenje

\footnotetext{
${ }^{2}$ Erik Bentli je najpoznatiji Brehtov prevodilac na engleski jezik.

${ }^{3}$ Nakon premijere u Minesoti, komad je do 1950. godine više puta insceniran na američkim koledžima.

${ }^{4}$ Samo dvanaest dana pre praizvedbe Dobrog čoveka iz Sečuana u Beogradskom dramskom pozorištu.
} 
Sovjetskog saveza od nacističkih trupa, koji je u delu predstavljen gotovo utopistički, kao emancipovano društvo u kojem se konflikti rešavaju argumentima.

Uprkos tome, drama je ostvarila uspeh na međunarodnom nivou nakon gostovanja Berlinskog ansambla u Parizu (20-24. jula 1955). Uz Majku Hrabrost, koja je samo godinu dana ranije na prestižnom Festivalu nacija osvojila prvu nagradu, nagrada koju je trupa dobila 1955. godine s Kavkaskim krugom, predstavlja drastični preokret u istoriji Brehtove recepcije (Ullmann, 1976: 112114), koji je usledio nakon decenija kontroverzi oko ličnosti autora i navodnog formalizma zbog kojeg je epsko pozorište diskreditovano čak i u zemljama Istočnog bloka, pre svega zahvaljujući Đerđu Lukaču i njegovim sledbenicima (Müller, 2009: 21; 23). Počev od tog perioda, Brehtovi komadi počinju da se izvode širom sveta, dakle, u trenutku ,kada [ga] više nije bilo moguće ignorisati” (Mitrevski, 2016: 152).

\section{2. Kavkaski krug kredom na srpskim pozornicama}

Prema podacima na kast-listi, „KAVKASKI KRUG KREDOM, drama u pet činova sa predigrom (41 slika)", premijerno je prikazana 26. marta 1963. godine u Narodnom pozorištu u Beogradu, kao prvi Brehtov komad koji je ovo pozorište izvelo (Volk, 1990: 564). Režija je pripala poznatom jugoslovenskom reditelju Bojanu Stupici, koji je koristio postojeći prevod Gustava Krkleca ${ }^{5}$. Iako je kritika afirmativno pisala o predstavi (Rnjak, 1972: 34), Stupičina inscenacija Kavkaskog kruga kredom za sada je ostala usamljen slučaj u istoriji srpskog pozorišta. Klabundov Krug kredom, međutim, insceniran je već 1953. godine (Volk, 1990: 975), iako je ovaj nemački pisac, za razliku od Brehta, u srpskoj kulturi danas gotovo nepoznat.

\footnotetext{
${ }^{5}$ Bojan Stupica je 1957. godine režirao komad po istom prevodu u Hrvatskom narodnom kazalištu u Zagrebu, zbog čega se ove dve inscenacije gotovo ne razlikuju. On je režirao i najviše Brehtovih komada u bivšoj Jugoslaviji: Opera za tri groša (Slovensko narodno gledališče u Ljubljani, 1937), Kavkaski krug kredom (Hrvatsko narodno kazalište u Zagrebu, 1957), Opera za tri groša (Jugoslovensko dramsko pozorište u Beogradu, 4. mart 1959), Snoviđenja Simone Mašar (Pozorište „Boško Buha” u Beogradu, 14. mart 1963) i Kavkaski krug kredom (Narodno pozorište u Beogradu, 26. mart 1963).
} 


\section{KRUG KREDOM TATJANE ŠENK I JOVANA ĆIRILOVA: ANALIZA PREVODILAČKOG POSTUPKA ${ }^{6}$}

Za razliku od Kruga kredom, prevod Majke Hrabrost (Breht, 1964) Tatjane Šenk $^{7}$ i Jovana Ćirilova u Srbiji je doživeo veliki uspeh, o čemu svedoče tiraži u kojima je štampan, kao i činjenica da je preveden na Brajevo pismo (Mitrevski, 2013: 18). S obzirom na motivsku povezanost ovih dvaju komada, zanimljivo je interesovanje prevodilaca za problematiku majčinstva, koja je, osim toga, u oba dela smeštena u kontekst rata. Nije isključeno da je Ćirilov, kao „sasvim pronicljiv pozorišni delatnik [koji] poznaje sve teatarske mehanizme" (Putnik, 1997: 140), pretpostavio kako će se ovi komadi uklopiti u poetiku socijalističkog realizma, čime bi, s jedne strane, ,udovoljio" institucijama, s druge strane edukovao publiku o savremenim pozorišnim zbivanjima, što je godinama činio u okviru Bitefa (Ćirilov, 2002: 23-26). To je istakao i Putnik (1997: 140): ,[Jovan Ćirilov] veoma dobro zna zakučaste i neizbežne tokove pozorišnog života - zvaničnog i onog nezvaničnog koji je često odlučujući za status predstave i teatra u javnosti [...]."

Osim što se ne pominje u sekundarnoj literaturi, ni sam Ćirilov u razgovoru iz 2013. godine nije naveo Kavkaski krug kredom. Ono što je značajno, a čega se živo sećao, jeste da je 1954. godine s Minjom Dedićem na Festivalu nacija u Parizu gledao Majku Hrabrost u izvođenju Berlinskog ansambla, sa „impresivnom” Helene Vajgel u glavnoj ulozi. Stoga nije isključeno da je i naredne godine ispratio nastup ove trupe, koju je predvodio po njemu „najbolji pisac među takozvanim piscima levičarima" (Mitrevski, 18. jun 2013). Pretpostavka je utoliko značajna, jer bi u slučaju da je tačna, opcije vezane za godinu nastanka prevoda bile sužene na period ubrzo nakon Festivala kao i to da pozorišta potencijalno još nisu bila

\footnotetext{
${ }^{6}$ Prevod je analiziran po kombinovanom modelu Lamber/fan Gorpa (Josè Lambert/ Hendrik van Gorp) i Gideona Turija (Gideon Toury) i on „obuhvata 'sve funkcionalno relevantne aspekte' prevođenja, uključujući tekst originala i tekst prevoda, autora u izvornoj i autora u ciljnoj kulturi (prevodioca), kao i [recipijente u oba sistema (kulture), te] njihove međusobne odnose. [...] Prema ovom modelu, analiza se sastoji iz sledeća četiri koraka: analize preliminarnih podataka, analize na makro nivou i utvrđivanja 'prihvatljivosti' prevoda s aspekta ciljne kulture, analize na mikro nivou [(ključna faza) i najzad,] sistemskog konteksta" (up. Mitrevski, 2013: 7-9).

${ }^{7}$ O Tatjani Šenk u literaturi nema čak ni osnovnih ličnih podataka. Od Ćirilova se zna da je bila supruga slovenačkog reditelja Janeza Šenka, kao i da je odlično vladala nemačkim jezikom. Prevodilački proces, kako je naveo, izgledao je tako što je ona prevodila s nemačkog na srpski, koji nije tako dobro govorila, pa bi Ćirilov tu verziju sređivao.
} 
spremna da izvode ovaj ,socijalistički komad” (otuda štrihovanje u naslovu) u vreme nestabilnih diplomatskih odnosa sa Sovjetskim savezom.

\section{1. Analiza preliminarnih podataka}

$\mathrm{Na}$ koricama sveske nalaze se sledeći podaci: „СРПСКО НАРОДНО ПОЗОРИШТЕ У НОВОМ САДУ / БИБЛИОТЕКА ДЕЛА И УЛОГА / Број: 675/ IV / KRUG KREDOM / Komad za mladež u pet činova s predigrom / Писац Bert Breht / Preveli Tatjana Šenk i Jovan Ćirilov / [Za] STUDIJU” (SNP, inv. br. $675 / \mathrm{IV})$. Nema podataka vezanih za datum nastanka prevoda, kao ni imena reditelja i dramaturga. U samom tekstu koji je veoma očuvan nisu vidljivi tragovi štrihovanja niti dopisivanja. Kucan je na pisaćoj mašini, ćiriličnim pismom, sem naslovne strane koja je pisana latinicom, a obima je sedamdeset sedam strana. Kraj je eskplicitno naznačen (,KPAJ”, SNP, inv. br. 675/IV: 77).

Podnaslov komada, koji je ujedno i žanrovska odrednica, utoliko je neobičan, jer nije poznat u Brehtovom opusu, ako se izuzmu poučni komadi (nem. Lehrstücke) pisani za ovu ciljnu publiku. Povrh svega, nejasno je zbog čega je iz samog naslova izostavljen pridev „kavkaski”, osim što je komad time dobio opštiji smisao. Pretpostavka da je tandem na taj način želeo da ,zataška” sporno mesto za sada je jedina objašnjiva, iako trenutno nije uočeno da su nazivi drugih sovjetskih lokaliteta zamenjeni drugim.

\section{2. Analiza na makro nivou i utvrđivanje ,prihvatliivosti" prevoda s aspekta ciljne kulture}

Ovaj ,komad za mladež” podeljen je na pet činova i predigru. Unutar činova, koji su obeleženi rimskim brojem i sadrže naslov, ne postoje manje kompozicione jedinice, odnosno, one ni na koji način nisu naznačene. Isto tako, na početku ne postoji uobičajeni spisak lica, zbog čega se o njihovim međusobnim odnosima i vezama saznaje postupno, u toku radnje.

U skladu s personalom drame, u kojoj su protagonisti „obični ljudi”, u prevodu dijaloga dominira kolokvijalni jezik s primesama vulgarne leksike i mnoštvom ,narodskih” izraza, dok stihovi naratora Arkadija Čajdzea kako stilski tako i formalno naglašavaju epsku crtu komada. Upravo ta mesta u prevodu mogla bi se okarakterisati kao veoma prihvatljiva, što nimalo ne čudi, ako se ima u vidu izuzetno razvijena epska poezija u okviru srpske književnosti, koju prevod na taj način evocira: 
[...] „Slušaj, ženo, ko na pomoć jednom se ogluši,

Nikad više poziv dragog neće osluhnuti,

Nikad više pesmu kosa jutrom ćuti [sic]

Nikad uzdah žeteoca na večernju." (SNP, inv. br. 675/IV: 19).

$\mathrm{Na}$ ova mesta bi prilikom dalje analize trebalo obratiti naročitu pažnju, jer ona najčešće predstavljaju indikator za veće izmene izvornika u cilju njegovog prilagođavanja potrebama ciljne kulture (Bassnett, 1998: 96).

Određena prevodilačka rešenja nedvosmisleno predstavljaju primere akulturacije izvornika. Osnovana sumnja javlja se već u vezi s titulom „ban” (SNP, inv. br. 675/IV: 7), koja se na ovim prostorima koristila sve do 1941. godine, a koja u nemačkom jeziku nema potpuni pandan. Kao naročit pokazatelj ovakve prevodilačke strategije može se smatrati i „naricanje” (SNP, inv. br. 675/IV: 18), danas zastareli običaj koji je svojstven slovenskim narodima, zatim korišćenje pojmova poput „gibanice” (SNP, inv. br. 675/IV: 39) ili izraza „ispičuturo”(SNP, inv. br. 675/IV: 73), koji su upotrebljeni upravo sa ciljem da tekst približe ciljnoj kulturi, time što će nepoznate ili manje frekventne reči i izraze zameniti autohtonim.

Kada je reč o kompleksnijim jezičkim tvorevinama (narodne umotvorine, uobičajena poređenja, frazeologizmi u širem smislu) načelna preporuka je da se one u prevodu zamenjuju postojećim izrazima u ciljnoj kulturi, ili, ako takvi ne postoje sa sinonimnim značenjem, opisno. Ovo ,pravilo” ne treba shvatiti previše usko, jer pojedine frazeologizme - premda vrlo retko, kako se pokazalo u prevodilačkoj praksi - upravo treba prevoditi doslovno. To se odnosi isključivo na tzv. autorski frazeologizam (nem. Autorphraseologismus), koji je u Brehtovim dramama često prisutan (Kovač-Mitrevski, 2019: 128-132). U prevodu Kruga kredom uočava se donekle suprotan princip, zbog čega navedeni izrazi za čitaoca u manjoj ili većoj meri ostaju tzv. tamno mesto, a svakako su prilično upadljivi. Može se, na primer, lako zaključiti šta znači izraz „Ne može se bunar rosom napuniti” (SNP, inv. br. 675/IV: 69) ili „vrata su na svojim šarkama” (SNP, inv. br. 675/IV: 45), ali je nejasno šta se krije iza Azdakovih reči upućenih Prosjaku: „trčiš kao slina u aprilu” (SNP, inv. br. 675/IV: 48). Jedina osnovana sumnja odnosi se na glagol „laufen”, čije je osnovno značenje trčati, ali se koristi i u velikom broju kolokacija, kod kojih se pojedini elementi u srpskom jeziku razlikuju, kao što je i ovde slučaj. Dok u nemačkom nos doslovno trči ('jdm. läuft die Nase'), u srpskom jeziku on curi, a doslovan prevod ove igre rečima rezultirao je besmislicom. Kod nekih frazeologizama je pak slučaj da su nevešto prevedeni: „Sa drugim tvoji izgledi bi bili manji nego da kokoš stekne zube u kljunu" (SNP, inv. br. 675/IV: 67), ali je 
slika koja stoji iza ovog brehtovskog poređenja razumljiva. U ovom kontekstu je interesantno da su se Šenk/Ćirilov odlučili za doslovno preuzimanje izraza „zdrava kao riba u vodi" (SNP, inv. br. 675/IV: 14), iako u srpskom jeziku postoji poređenje „biti zdrav kao dren”, naročito jer se pokazalo da tendiraju zameni elemenata strane kulture.

Ukoliko se zanemare gramatičke i pravopisne greške, koje su česte u prevodima dramskih tekstova nastalim za potrebe inscenacije, opšti utisak prihvatljivosti prevoda narušava niz tzv. „sumnjivih mesta”. Čitalac će se u više navrata zapitati koji je smisao određene replike ili nekog njenog dela u datom ko(n)tekstu, jer se na osnovu njega značenje ne može odgonetnuti, čak ni ako se uzme da je posredi doslovan prevod s nemačkog jezika. Utisak je, pored navedenog, da se broj takvih mesta povećava kako tekst odmiče, pa se pretpostavlja da je prevod nastao u kratkom vremenskom roku, kao i da nije revidiran. ${ }^{8}$

\section{3. Analiza na mikro nivou}

Nakon upoređivanja prvih nekoliko stranica prevoda i originala, stiče se utisak da su prevodioci nastojali da zadrže što više iz izvornika. Postoji tek poneki primer štrihovanja, što je za prevode pozorišnih tekstova neuobičajeno, ali i vrlo malo izmena bilo koje vrste, ili su te izmene neznatne. Ako se pak zađe u dublju analizu, uočavaju se manipulacije izvornika koje prethodno nije bilo moguće ustanoviti.

Pored očiglednih primera, $\mathrm{u}$ prevodu postoje mnogobrojna doslovno prevedena mesta, koja su ,zamaskirana” i, prema tome, uočljiva tek ako se konsultuje izvornik, poput Jusupove ironične opaske da je „verenik [...] već opran, a verenica ljuta" (SNP, inv. br. 675/IV: 39), za koju se ispostavlja da u originalnom tekstu ima potpuno drugo značenje: „Der Bräutigam ist schon gewaschen, und die Braut ist schon scharf” (Brecht, Bd. 8, 1992: 50). Kako prevod prideva „scharf” u osnovnom značenju ljut(a) umesto nekim od žargonskih izraza za iskazivanje seksualne uzbuđenosti tako i prevod rečenice: „Der Azdak trinkt schwer” (Brecht, Bd. 8, 1992: 83) doslovno: „Azdak teško pije” (SNP, inv. br. 675/IV: 69), u smislu mnogo pije ili dobro potegne (njegov lik je, između ostalog, okarakterisan kao alkoholičar), potencijalno ukazuju na nedovoljno poznavanje prevodilaca govornog nemačkog jezika ili barem svih njegovih nijansi. Osim toga, neki od primera

\footnotetext{
${ }^{8}$ Zbog obima rada, ta mesta će u nastavku biti predočena isključivo u onoj meri u kojoj predstavljaju pokazatelj drastičnijih izmena izvornika.
} 
doslovnog prevođenja rezultirali su koliko rogobatnim jezičkim tvorevinama toliko besmislenim prizorima, kao u sceni suđenja iz četvrtog čina, u kojoj se pominje „invalid na stolici na točkovima” (SNP, inv. br. 675/IV: 58), gde u originalu zapravo piše „ein Invalide im Rollstuhl” (Brecht, Bd. 8, 1992: 70), dakle, invalidska kolica, a cela slika time je dobila komičan, čak bizaran prizvuk.

Ono što se u prevodu Kruga kredom ističe kao njegova bitna karakteristika jesu mnogobrojne manipulacije izvornika uslovljene kulturološkim razlikama. Mnogi pojmovi, izrazi i poređenja zamenjeni su poznatim ili uobičajenim. Uglavnom su u pitanju termini iz domena religije, zatim oni vezani za hranu i piće, običaje i pravosuđe, a prisutni su i tipični lokaliteti i, uopšte, tipične predstave ciljne kulture: „kad smo se borili kao partizani u ovim šumama” (SNP, inv. br. 675/IV: 3), u originalu: „als wir als Partisanen in diesen Hügeln kämpften” (Brecht, Bd. 8, 1992: 11), jeste slika vezana za Drugi svetski rat koja je prisutna i u poznatoj partizanskoj pesmi s tom tematikom (Po šumama i gorama, 1941). Takođe se pretpostavlja da je karakterizacija sudije kao predstavnika sudske vlasti, u izjavi Prvog oklopnika: „Immer war der Richter ein Lump, so soll jetzt ein Lump der Richter sein" (Brecht, Bd. 8, 1992: 69) ciljano izmenjena upotrebom izraza koji oslikava tipičnu predstavu o sudiji u ciljnoj kulturi: „Uvek je sudija bio lopov, neka sada jednom lopov bude sudija" (SNP, inv. br. 675/IV: 57).

Kada je reč o terminima iz domena religije, njihova zamena opštijim, poznatim pojmovima i izrazima, sprovedena je dosledno. Svugde gde se u izvorniku javlja „Jesus Maria” (Brecht, Bd. 8, 1992: 21) u bilo kojoj varijanti, Šenk/Ćirilov prevode neutralnim „Bože, Bože!” (SNP, inv. br. 675/IV: 12). Vidi se da je kontekst i te kako uzet u obzir prilikom prevođenja, pa su na jednom mestu proširili ovaj izraz: „Bože sačuvaj, jahači!” (SNP, inv. br. 675/IV: 26), što je u izvorniku „Jesus Maria, Panzerreiter!” (Brecht, Bd. 8, 1992: 36). Uzvik Gostiju kada Jusup, koji je do tada bio na samrti, ustane iz postelje: „Jesus Maria und Josef! Jussup!” (Brecht, Bd. 8, 1992: 52) prevodioci su rešili zamenom pojedinačnih imena sa „Bože moj! Svi sveti! Jusup!” (SNP, inv. br. 675/IV: 41), pri čemu je na taj način komičan efekat donekle oslabljen, jer se u originalu Jusupovo ime pominje na kraju ovog niza, čime je svrstan u red svetaca. Zanimljivo je da su repliku „Kruzifix, wie soll ich mit so einem Untergebenen den Gouverneursbankert finden, das möcht ich wissen" (Brecht, Bd. 8, 1992: 33), u kojoj se javlja raspeće, pojam koji se u ciljnoj kulturi u ovom značenju ne upotrebljava, Šenk/Ćirilov uspeli da prevedu koristeći ustaljeni izraz koji se takođe vezuje za religiju: „Boga mu, kako sa ovakvim ljudima da nađeš ono banovo kopile" (SNP, inv. br. 675/IV: 23), pri čemu je uočljivo pomeranje na stilskom nivou. Sličan postupak primenili su i u prevodu replike 
Kuvarice, koja pre početka suđenja izgovara: „Ich glaub, ich bet besser schnell noch einen Rosenkranz” (Brecht, Bd. 8, 1992: 79), gde imenica „Rosenkranz” kao deo kolokacije uz glagol „beten” u katoličkoj veroispovesti podrazumeva nizanje određenih molitvi po ustaljenom redosledu (molitva krunice), što je u prevodu uopšteno: „Mislim, da bolje još na brzu ruku očitaš molitvu uz brojanicu” (SNP, inv. br. 675/IV: 66), pri čemu je imenica „Rosenkranz” u svom osnovnom značenju (brojanica) prisutna kao dopuna u vidu adverbijala.

Naročito je zanimljivo što prevodioci biraju terminologiju vezanu za državno i društveno uređenje koje je nekada postojalo na našim prostorima, kao i regionalizme $u$ prevodu stilski nemarkiranih izraza umesto standardnih. Tako se $\mathrm{u}$ prevodu umesto poreza javljaju ,nameti” koji su ,pregolemi” (SNP, inv. br. 675/IV: 7), u originalu: „die Steuer ist unerschwinglich” (Brecht, Bd. 8, 1992: 15). Umesto standardnog izraza, u replici „Worauf wartest du, Bauernprügler?” (Brecht, Bd. 8, 1992: 59), Šenk/Ćirilov upotrebili su vojvođanski naziv za bič u prenesenom značenju; „Šta još čekaš ti seljačka kamdžijo?” (SNP, inv. br. 675/IV: 48), koji je znatno efektniji od bilo kog „knjiškog” prevoda, koji bi u ovom slučaju bio poguban po stil. Takođe su odabirom regionalizma u replici „Reportier, Plattfuß (Brecht, Bd. 8, 1992: 62) postigli da prevod bude u duhu srpskog jezika, a značenje jednako uvredljivo kao u originalu: „Raportiraj dustabanlijo!” (SNP, inv. br. 675/IV: 50). Sva ova mesta deluju veoma prihvatljivo s aspekta ciljne kulture, i svedoče o umešnosti prevodilaca.

Kod prevođenja ličnih imena uočava se neujednačen pristup. Pored transkripcije, kao dominantnog postupka, i ovde je prisutna akulturacija, koja je postignuta dodavanjem uobičajenih sufiksa. Pevač „Arkadi Tscheidse” u prevodu je "Akadije”, a isto je i s banom (guvernerom), čije je ime "Georgi Abaschwilli" (Brecht, Bd. 8, 1992: 8), koje je prevedeno kao „Georgije” (SNP, inv. br. 675/IV: 16), kao i „Lavrenti” (Brecht, Bd. 8, 1992: 33; 43) - „Lavrentije” (SNP, inv. br. 675/IV: 32; 33; 42) i „Wassili” (Brecht, Bd. 8, 1992: 49) - „Vasilije” (SNP, inv. br. 675/IV: 38). Banov sin, o kojem se Gruše stara, „Michel” (Mihel), u prevodu je posrbljen: „Mića” (SNP, inv. br. 675/IV: 22), a ispostavilo se da su prevodioci napravili veliku grešku kada su repliku: „Wir haben den richterlichen Befehl, dieses Kind, angetroffen in deiner Obhut, in die Stadt zu bringen, da der Verdacht besteht, es ist Michel Abaschwilli, Sohn und Erbe des verstorbenen Gouverneurs Georgi Abaschwilli und seiner Frau Natella Abaschwilli." (Brecht, Bd. 8, 1992: 58) preveli na sledeći način: „Imamo naređenje od suda da dete nađemo pod tvojim starateljstvom, dovedemo u grad, pošto postoji sumnja da je to sin Mihajla Abašvilija i njegove žene Nataše Abašvili” (SNP, inv. br. 675/IV: 47). To isprva ne 
čudi, pošto je ime deteta u prevodu Mića, a Mihel („Mihajlo”) se prethodno ne pominje. Ako se pak uzme u obzir da se nešto kasnije u delu pojavljuje i ime „Mihel” (SNP, inv. br. 675/IV: 71), ovog puta u vezi s detetom, to je za recipijenta u ciljnoj kulturi zbunjujuće, i do kraja ostaje nejasno koje ime je ispravno.

Prevođenje frazeologizama u Brehtovim dramama naročito je zahtevan prevodilački poduhvat (Kovač-Mitrevski, 2019: 128-132). Pored leksikalizovanih frazeologizama, i u ovom delu se javljaju autorski frazeologizmi, čije značenje treba odgonetnuti, a zatim i preneti u drugi kulturni kontekst. Tu se najbolje vidi kako je prevođenje književnog dela ponekad "slepa spona od nemog do gluvog" (Živojinović, 1981: 278). Šenk/Ćirilov su se vešto snašli kada su pitanje Prvog oklopnika „Was ist das für ein komischer Vogel?” (Brecht, Bd. 8, 1992: 62), koje postavlja kada ugleda Azdaka, preveli „Kakav je to čudan svetac?” (SNP, inv. br. 675/IV: 50), a isto se može reći i za teži zadatak, kada su autorski frazeologizam „Das Entenjunge ist ein Schwimmer, heißt es.” (Brecht, Bd. 8, 1992: 55) preveli „Ribu još niko plivanju nije učio!” (SNP, inv. br. 675/IV: 44) nastojeći da prenesu sliku upotrebom srodnih leksema. Vrlo interesantan primer u prevodu predstavlja i aluzija na poznatu izreku u Grušinoj replici ,prišla sam ti kao breg Muhamedu” (SNP, inv. br. 675/IV: 36), koja je zajednička za ceo evropski kulturni prostor, budući da, kako se smatra, vodi poreklo od engleskog filozofa Frensisa Bejkona (Francis Bacon), koju pominje u svom delu Eseji (1625). U originalu, kako se ispostavilo, ne postoji aluzija na izreku „Wenn der Berg nicht zum Propheten kommt, muss der Prophet wohl zum Berge kommen”, već je posredi „Ich bin zu dir gekommen wie der Birnbaum zu den Spatzen" (Brecht, Bd. 8, 1992: 46), što je takođe originalna Brehtova tvorevina ${ }^{9}$. I kod prevođenja frazeoloških izraza, prema tome, dominira postupak akulturacije.

Songovi naročito doprinose utisku prihvatljivosti prevoda s aspekta ciljne kulture. Prevedeni su vrlo vešto, s tim što se ujedno potvrdila hipoteza da je upravo na tim mestima u prevodu prisutno više izmena, kao u pomenutim stihovima ([...] „'Slušaj, ženo, ko na pomoć jednom se ogluši, / Nikad više poziv dragog neće osluhnuti, / Nikad više pesmu kosa jutrom ćuti [sic] / Nikad uzdah žeteoca na večernju."”, SNP, inv. br. 675/IV: 19), koji u originalu glase:

\footnotetext{
${ }^{9}$ Nije isključeno da Breht ovde aludira na nemačku parabolu Der Holzhacker und sein Sohn (Sämmtliche Werke: mit Stahlst. Parabeln, Sagen u. Erzählungen, Bd. 38 (1847). Regensburg: Verlag von S. Joseph Manz, 10) budući da parabola predstavlja glavno formalno sredstvo epskog pozorišta.
} 
$[\ldots]$

„Wisse, Frau, wer einen Hilfeschrei nicht hört

Sondern vorbeigeht, verstörten Ohrs: nie mehr

Wird der hören den leisen Ruf des Liebsten noch

Im Morgengrauen die Amsel oder den wohligen

Seufzer der erschöpften Weinpflücker beim Angelus.” (Brecht, Bd. 8, 1992: 29).

Dok je u izvorniku prisutan „Seufzer der erschöpften Weinpflücker beim Angelus”, $\mathrm{u}$ prevodu je ta slika zamenjena drugom, koja ima za cilj da kod recipijenata $\mathrm{u}$ ciljnoj kulturi izazove iste asocijacije („Nikad uzdah žeteoca na večernju”). Kao poseban vid akulturacije mogu se smatrati i formalne izmene originalne strofe $\mathrm{u}$ kojoj je dominantan stilski postupak opkoračenje (1-4), uvođenjem anafore (2-4) koja je česta stilska figura u srpskoj narodnoj poeziji. U prevodu je dejstvo ove pesme, kojom Arkadi Čajdze u prelomnom trenutku u okviru drame izveštava o Grušinom kolebanju, pojačano ponavljanjem priloga „nikad”, što za nju predstavlja neku vrstu opomene, nakon čega odluči da povede ostavljeno dete, iako svesna da se time izlaže opasnosti. Na ovom primeru takođe se vidi opšte načelo kojim su se Šenk/Ćirilov vodili, koje se odnosi na skraćivanje stihova koje su smatrali suvišnim (1-2), kao i da je njihovo značenje u prevodu nadomešćeno drugim izražajnim sredstvima. Druga strofa uvodnog songa iz drugog čina u originalu glasi:

Wie will die menschliche entkommen

Den Bluthunden, den Fallenstellern?

In die menschenleeren Gebirge wanderte sie

Auf der georgischen Heerstraße wanderte sie

Sang sie ein Lied, kaufte Milch (Brecht, Bd. 8, 1992: 30).

Slično prevodu naslova, u kojem je izostavljen atribut „kavkaski” i čime je delo dobilo opštiji smisao, ovde je prisutna parcijalna zamena predloške fraze „Auf der georgischen Heerstraße", koja iskazuje lokalitet kojim se Gruše u tom trenutku kreće:

Da li će izmaći

Krvnicima, izmaći ubojicama?

Kroz puste gore lutala je

Kroz divlje šume lutala je

Pesmu je pevala, mleko kupovala. (SNP, inv. br. 675/IV: 21)

Izmena može biti motivisana kako leksemom „gore” (3. stih) tako i leksemom „Heerstraße”, budući da se vojska za vreme Drugog svetskog rata najčešće kretala šumom, kao i da ta slika postoji u svesti recipijenata u ciljnoj kulturi. Osim toga, vidi se da je pridev „,georgisch” u prevodu zamenjen pridevom „divlji”, što s jedne 
strane ima veze kako s metrikom tako i sa stilskom figurom koja je na taj način preneta i u prevodu, dok, s druge strane, ovaj primer potencijalno ukazuje na tendenciju prevodilaca da izostave sva sporna mesta, ako se uzme u obzir vreme nastanka prevoda.

\section{4. Sistemski kontekst}

$\mathrm{Na}$ osnovu karakteristika samog prevoda, kao i propratnih okolnosti njegove recepcije, pretpostavlja se da je Krug kredom nastao ubrzo nakon izvođenja Berlinskog ansambla 1955. godine na Teatru nacija u Parizu, kojem je Ćirilov najverovatnije prisustvovao. Pored izmenjenog naslova i dopisane žanrovske odrednice, na takav zaključak navode i mnogobrojne manipulacije izvornika za potrebe ciljne kulture, koje potencijalno ukazuju na pokušaj prevodilaca da izbegnu cenzuru usled nepovoljnih diplomatskih odnosa između Jugoslavije i Sovjetskog saveza, koji su se privremeno stabilizovali tek nakon 1956/7. godine.

Komad je premijerno prikazan 1963. godine na sceni Narodnog pozorišta u Beogradu, kada je Breht bio uveliko poznat. Za ovu, jedinu inscenaciju Kavkaskog kruga kredom u Srbiji, reditelj Bojan Stupica koristio je prevod Gustava Krkleca. Krug kredom u prevodu Tatjane Šenk i Jovana Ćirilova nikada nije postavljen na scenu srpskih pozorišta.

Prevod odlikuje niz primera akulturacije i on je ujedno pokazatelj u kojoj meri je dramski tekst vezan za kontekst u kom nastaje, odnosno, zbog čega se prenošenjem u drugi sistem nužno menja. S obzirom na pretpostavljeni period njegovog nastanka, pored imena dramskog personala, naročito treba istaći izmene vezane za pojmove iz domena religije, koji su u originalu nedvosmisleno preuzeti iz katoličke konfesije, dok su u prevodu neutralizovani. Štaviše, Kavkaski krug kredom pokazao se veoma pogodnim upravo sa ovog aspekta, jer sadrži niz kulturno specifičnih pojmova i izraza. Pored toga, ustanovljeno je koji delovi originala su štrihovani, zatim na kojim mestima je tekst proširen u prevodu, kao i mnogobrojne supstitucije.

Sudeći po broju reditelja i prevodilaca koji su pokazali interesovanje za Brehtov komad Kavkaski krug kredom, on je u srpskoj kulturi naišao na neuporedivo manji odjek od Majke Hrabrost ili Opere za tri groša. Ako se pritom uzme u obzir da je Klabundov Krug kredom insceniran deceniju ranije, sve 
navedene činjenice vezane za recepciju Brehtovog dela navode na zaključak da su faktori za njegovo odbijanje bili prvenstveno vanjezičke prirode. ${ }^{10}$

\section{ZAKLJUČAK}

Nepublikovani prevod Brehtovog komada Krug kredom iz pera Tatjane Šenk i Jovana Ćirilova, koji je najverovatnije bio pokušaj da se srpskoj publici prikaže jedan od najvećih komada savremenog nemačkog dramatičara, nastao je u drugoj polovini pedesetih godina prošlog veka. Na osnovu odlika samog prevoda, kao i svih ostalih činjenica vezanih za njegovu negativnu recepciju, ovaj prevod je pokazatelj koliko je jaka sprega zvanične (kulturne) politike i prevodne književnosti. Ona se podjednako ogleda u odabiru dela, prevodiočevoj odluci da nešto (ne) prevede, ali i u načinu na koji će delo prevesti. U tom smislu, analiza prevoda Kruga kredom, kao i njegove recepcije potvrđuje da proučavanje prevodne književnosti, naročito dela dramske produkcije, pruža bogatu građu za proučavanje ciljne kulture i međukulturnih veza.

\section{Ana Mitrevski}

\section{BRECHT'S DRAMA THE (CAUCASIAN) CHALK CIRCLE TRANSLATED BY TATJANA ŠENK AND JOVAN ĆIRILOV}

\section{Summary}

Brecht's position of a socially engaged playwright is incessantly associated with the events taking place at that time on the world's social and political stage. It was after his decision to move to East Berlin, where he spent the rest of his life, that he became a target of ideological controversy which, until the fall of the Eastern bloc, directly influenced the reception of his works as well.

Referring to the foreign literature in translation, the connection of the official and cultural policy is visible in both the selection of the works which shall (not) be translated and in the way they will be translated i.e. the translation poetics. Since the drama plays written after the war showed the lowest progress, the repertoires of great Serbian theatres were

\footnotetext{
${ }^{10}$ Činjenica da je komad 2019. godine prikazan u okviru pozorišnog festivala Novi tvrđava teatar (Miletić, 2019: 19-24), za koju je reditelj Paolo Mađeli (Paolo Magelli) sa trupom Narodnog pozorišta Sarajevo osvojio prvu nagradu, potencijalno svedoči o interesovanju za samog autora, čija se dela u poslednjih nekoliko decenija retko viđaju na srpskim pozornicama.
} 
dominated by the foreign authors, so we could conclude that the foreign literature in translation played a major role in the revival of the theatrical life in Serbia of the time.

The reception of Brecht's epic theatre started with the premiere of The Good Person of Szechwan (Der gute Mensch von Sezuan, 1941), staged on October 19, 1954 in the Belgrade Drama Theatre (Beogradsko dramsko pozorište), which marked this playwright's breakthrough in the Yugoslav theatre stages. Up to the present, all of the Brecht's works designated as epic theatre have been translated into Serbian, and some of them have been translated several times. Despite good reception of his translated drama production, there are only a few studies related to the translation of Brecht's plays. Apart from that, among the translations, there are several of them unaccounted for in the secondary literature, whether it is about the newspaper's headlines, reviews, or scientific publications.

This study shall present a so far unknown translation of Brecht's drama The (Caucasian) Chalk Circle (Der kaukasische Kreidekreis, 1944), kept in the library of the Serbian National Theatre in Novi Sad (Srpsko narodno pozorište Novi Sad), which presents a testimony of extremely rich and diverse reception of this author in Serbia.

It has been shown that the factors influencing the manner of reception of the works coming from the foreign culture in the stated social and historical context could be visible in the very translation, in accordance with the translation analyses and the reconstruction of the translation actions, as well as the interpretation of the results within the frame of the systemic context.

Keywords: Bertolt Brecht, The Chalk Circle, Tatjana Šenk, Jovan Ćirilov, translation reception, foreign literature in translation, the Serbian National Theatre library.

\section{LITERATURA}

Bassnett, S. (1998). Still Trapped in the Labyrinth: Further Reflections on Translation and Theatre. U: Bassnet, S.-Lefevere, A. (ed.) (1998). Constructing Cultures: Essays on literary Translation. Clevedon: s. n., 90109.

Brecht, B. (1991). Schriften 4: Texte zu Stücken. U: Hecht, W.-Knopf, J.Mittenzwei, W. \& Müller, K.-D. (Hrsg.) (1991). Werke: Große kommentierte Berliner und Frankfurter Ausgabe, Bd. 24. Frankfurt am Main: Suhrkamp-Berlin und Weimar: Aufbau-Verlag.

Brecht, B. (1992). Der kaukasische Kreidekreis. U: Hecht, W.-Knopf, J.Mittenzwei, W. \& Müller, K.-D. (Hrsg.) (1992). Werke: Große kommentierte Berliner und Frankfurter Ausgabe, Bd. 8. Frankfurt am Main: Suhrkamp-Berlin und Weimar: Aufbau-Verlag. 
Breht, B. (1964). Majka Hrabrost i njena deca: Hronika iz Tridesetogodišnjeg rata. Preveli s nemačkog Tatjana Šenk i Jovan Ćirilov. Beograd: Rad.

Ćirilov, J. (2002, januar-februar). Muke s avangardom. Scena: časopis za pozorišnu umetnost, 1, 23-26.

Deretić, J. (1987). Kratka istorija srpske književnosti. Beograd: BIGZ.

Đurić, D. (2002). Ideologija prevođenja. U: Janićijević, J. (ured.) (2002). Prevodna književnost: zbornik radova XXIII-XXVI beogradskih prevodilačkih susreta 1997-2001. Beograd: Udruženje književnih prevodilaca Srbije, 717-720.

Kittstein, U. (2008). Bertolt Brecht. Paderborn: Wilhelm Fink GmbH \& Co. Verlags-KG.

Knopf, J. (2006). Bertolt Brecht. Frankfurt am Main: Suhrkamp Verlag.

Kovač, B.-Mitrevski, A. (2019). Beiß die Zähne zusammen! Phraseologismen in Bertolt Brechts Die Dreigroschenoper und ihre Übersetzung ins Serbische. U: Gudurić, S.-Radić-Bojanić, B. (ured.) (2019). Jezici i kulture u vremenu i prostoru VIII/2: tematski zbornik. Novi Sad: Univerzitet u Novom Sadu, Filozofski fakultet, 125-134.

Miletić, T. (2019). 6 pozorišni festival „Novi tvrđava teatar”: 4-9. jula 2019 Vila Stanković, Črtanovci. Novi Sad: Udruženje građana „Novi tvrđava teatar” Novi Sad, 19-24.

Mitrevski, A. (18. jun 2013). Jovan Ćirilov o prevođenju Majke Hrabrost (Neobjavljeni audio zapis), Bitef teatar, Beograd.

Mitrevski, A. (2013). Prevođenje Brehtove drame Majka Hrabrost sa nemačkog na srpski jezik (Nepublikovani master rad). Filozofski fakultet, Univerzitet u Novom Sadu, Novi Sad.

Mitrevski, A. (2016). Brehtova Majka Hrabrost u vremenu i prostoru. U: Gudurić, S.-Stefanović, M. (ured.) (2016). Jezici i kulture u vremenu i prostoru $V$ : tematski zbornik. Novi Sad: Univerzitet u Novom Sadu, Filozofski fakultet, 149-154. (štampano ćirilicom)

Mitrevski, A.-Petrović, Đ. (2014). Problem ekvivalentnosti u prevodu Brehtove drame Dobar čovek Sečuana. U: Anđelković, M. (2014). Savremena proučavanja jezika i književnosti: zbornik radova sa $V$ naučnog skupa mladih filologa Srbije, knj. 2. Kragujevac: Filološko-umetnički fakultet u Kragujevcu, 615-622. (štampano ćirilicom)

Müller, K.-D. (2009). Bertolt Brecht: Epoche - Werk - Wirkung. München: Verlag C. H. Beck, 21; 23.

Pašić, F. (2007). Beogradsko dramsko pozorište 1947-2007. Beograd: Beogradsko dramsko pozorište. 
Putnik, R. (1997). Približavanje pozorištu: prikazi pozorišnih knjiga. Beograd: Narodno pozorište, 140.

Rnjak, D. (1972). Bertolt Brecht in Jugoslawien. Marburg: N. G. ELWERT VERLAG.

Sämmtliche Werke: mit Stahlst. Parabeln, Sagen u. Erzählungen, Bd. 38. (1847). Regensburg: Verlag von S. Joseph Manz.

Schneider, A. (1984). Brecht-Dramen auf Russisch: Problematik der Dramenübersetzung. München: Hieronymus.

Stolze, R. (2008). Übersetzungstheorien: Eine Einführung. Tübingen: Günter Narr. Šenk, T.-Ćirilov, J. (s. a.). Krug kredom. Novi Sad: Biblioteka Srpskog narodnog pozorišta, sign. 675/IV. (štampano ćirilicom)

Toma, S. (1979). Lirika Bertolta Brechta na srpskohrvatskom između dva rata (Nepublikovani magistarski rad). Filološki fakultet, Univerzitet u Beogradu, Beograd.

Ullmann, L. (1976). Wandlungen. Bern: Scherz Verlag.

Volk, P. (1990). Pozorišni život u Srbiji 1944/1986. Beograd: Institut za pozorište, film, radio i televiziju Fakulteta dramskih umetnosti.

Zobenica, N. (2015). Bertolt Breht i Istok. U: Popović, V.-Janjić, I.-Milancovici, S. \& Gagea, E. (ed.) (2015). Communication, Culture, Creation: New Scientific Paradigms. Arad: „Vasile Goldiș” University Press-Novi Sad: Fondatia Europa, 906-916.

Živojinović, B. (1981). Beleške o prevođenju. U: Rajić, Lj. (ured.) (1981). Teorija i poetika prevođenja. Beograd: Prosveta. 